Available online at www.sciencedirect.com ScienceDirect

\title{
Using Network Analysis to Build a New Business
}

\section{ROB CROSS ANA DUTRA}

\section{USING NETWORK ANALYSIS TO BUILD A NEW BUSINESS}

In the days after Anne Downing was tapped to lead the new business unit at one of the world's largest professional services organizations, she felt increasingly burdened by the pressure of taking over from Chris Smith, who had formed this group so rapidly and effectively. The overall company had an impressive track record, achieving a double-digit compound annual growth rate from 1989 to 2005 and a nearly $70 \%$ increase in head count from 2001 to 2005 . However, the firm was still not serving clients with offerings that many felt were a natural market. Smith had been hired to help build a specialist practice that would serve clients directly as well as become a key source of expertise for partners from the overall organization to pull into client engagements. He began his work with tremendous energy and savvy. No one was really surprised when, within a year and a half, he was promoted to the company's executive ranks. Downing, an experienced but new hire in the firm, was a natural successor, but the challenge she faced was two-fold: Not only did she have to maintain the momentum Smith had established, but her job was expanded to be global in scale. No longer could she rely on a loose-knit group of experts; she would have to quickly create a cohesive worldwide network able to rapidly respond to client needs.

Most managers today understand the importance of collaboration to the success of their companies. In an era of globalization, proliferating technology, and specialization

\author{
BOB THOMAS \\ CARRIE NEWBERRY
}

of knowledge-based work, accomplishments of any substance require more than streamlined processes; they require people to work together in ways that aren't fully captured on formal organizational charts or standardized processes and procedures. Important outcomes - revenue growth, patent approvals, cycle time reduction, client retention - are associated with effective collaboration and networks. By identifying and replicating productive network dimensions, executives can realize substantial growth and efficiency deep within their organizations. But taking action on these seemingly invisible networks can seem a daunting task. After all, how is a leader supposed to influence what he or she can't even see?

To tackle her new challenge, Downing decided to approach collaboration systematically. Rather than rely on a few energetic contributors or rush to install a much-hyped technological solution, she elected to start by asking a few basic questions: What networks were in place that leveraged the high-end expertise and project experiences within her business unit? What collaborations were established with other business units within the firm that would utilize her practices' specialist services? How much did her employees know about the depth of skills residing in the group (and so whom to tap when certain opportunities appeared)? How well were people sharing their skills and expertise with one another? And what incentives were most likely to encourage valueadded collaborations?

She could not answer these questions by looking at the practice's organizational chart 
or by reading people's job descriptions. To get the view of the group that she needed, Downing conducted an Organizational Network Analysis (ONA) to find targeted ways to improve collaboration among the leaders and high-end experts in the group. The analysis consisted of a 20-minute online survey that assessed information and knowledge flow as well as other important network characteristics (an abbreviated version of the survey is in Appendix A). Downing planned to use the results of the ONA to achieve the following objectives:

- Improve collaboration and information flow among the group to ensure that the best expertise was more systematically brought to bear on project sales and delivery efforts.

- Drive economic results (both productivity gains through knowledge transfer and revenue growth through sales collaborations) via improved connectivity.

- Enhance innovation and cross-selling of key services and expertise by better leveraging unique skill sets within the network.

- Embed network development practices into talent management processes to improve individual performance, retention and talent attraction.

\section{IMPROVING COLLABORATION}

The survey results dramatically illustrated one thing Downing already knew: Networks, not databases, were the key to information flow and solving client problems. When asked to rate the importance of various sources of information, her employees universally indicated that leveraging other colleagues in Downing's practice - not internal or external repositories - was the critical way they got information to do their work. To get a sense of these patterns of collaboration amongst her employees, she asked each employee to rate all other employees on the following question: "Please indicate the extent to which the following people are effective in providing you with information that helps you to learn, solve problems, and do your work." Many of the results really surprised her. For example, several people lower in the hierarchy were more central in the network than she had anticipated. She quickly realized that working with and through these well-connected up-andcomers would be important for revenue growth and sustainability of the practice over time. She was equally surprised to see how peripheral several key experts were and immediately vowed to better integrate them on sales calls and staffing of client engagements. Seeing the extent to which some of the world-class expertise in her practice was going untapped reinforced for Downing the extent to which her employees were falling into a trap of collaborating with just the people they already knew, rather than tapping the best expertise.

Overall, the information network (shown in Fig. 1a) revealed that people in the practice were less connected than she had hoped. Only $12 \%$ of possible collaborations existed, which was much lower than Downing had hoped. Given that collaboration needs to be relevant and people have limited time, 100\% connectivity would be highly undesirable, but something in the range of 25-35\% would be strong for this kind of group, based on benchmarks provided by The Network Roundtable. The analysis also revealed that, on average, each employee was 2.7 steps away from every other employee. This also concerned Downing, as research shows that most people are willing to go no more than two steps (for example, reaching out to a friend and then to a friend of a friend) for information. Downing wondered if employees were getting the information they needed, and if the people they reached out to were responding helpfully.

What Downing found so helpful about the network analysis was its specificity. She had seen network diagrams before in presentations, but they had always been abstract-lines and arrows connecting people she did not know or care about. These charts just did not capture the wealth of tacit 


\section{Fig. 1 (a) Information Flow and Collaboration; (b) Network Fragmentation}

(a)

"Please indicate the extent to which the following people are effective in providing you with information that helps you to learn, solve problems, and do your work."

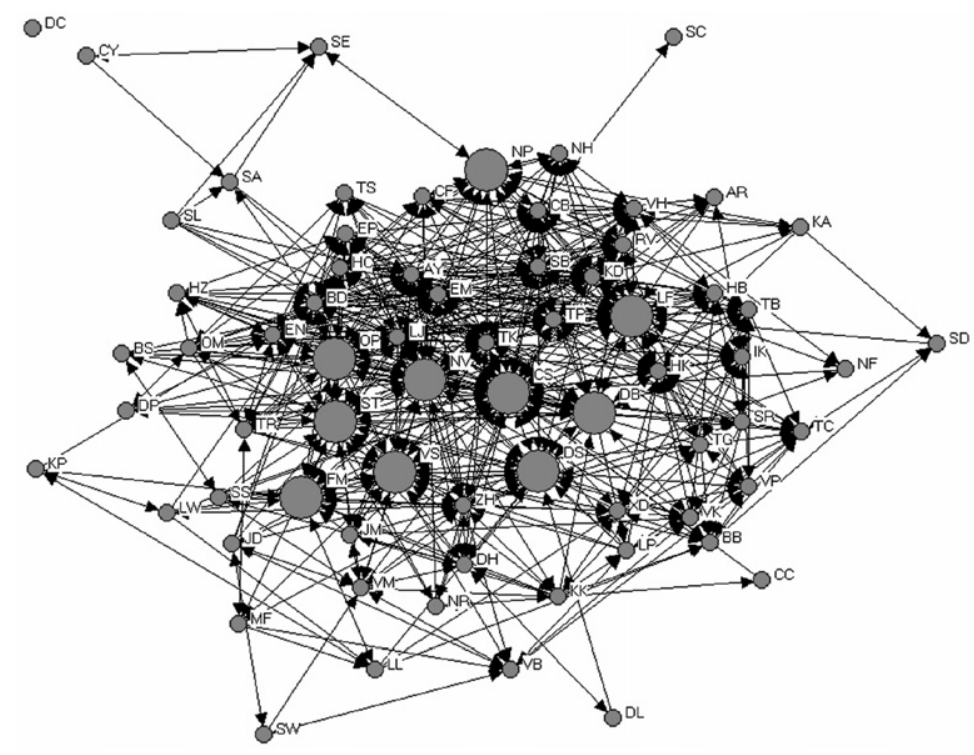

(b)

"Please indicate the extent to which the following people are effective in providing you with information that helps you to learn, solve problems, and do your work."

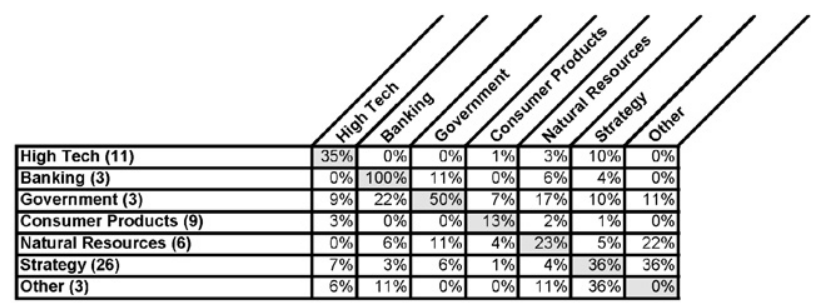

Individuals in industry groups (High Tech, Banking, Government, Consumer Products, and Natural Resources) have deep industry expertise, whereas individuals in the Strategy area have specialized skills. Collaboration between industry groups and Strategy is required to develop world-class customer solutions.

knowledge that she could clearly recognize when looking at connectivity of her own group. In striking contrast, these results jumped off the page at her as she immediately recognized opportunities for improvement based on her knowledge of the personalities, expertise, and to some degree the histories between people in the network.
She knew what would happen if she took a blanket approach to boosting connectivity by insisting that everyone use collaborative tools or start attending more meetings. She'd have a lot of disgruntled and unfocused employees on her hands wasting precious time just trying to randomly increase connectivity. These results allowed her to take a 
targeted approach that focused on building value-added ties much more efficiently and effectively.

For example, the analysis indicated that a group of 10 senior executives had become very central and influential in the network. These people were well-connected opinion leaders around specific topics. By simply publicizing these people as "go-to" experts (on topics they were already being sought out for), strengthening the connections among these central members (identified as larger circles in Fig. 1a) through a bi-weekly call and encouraging them to connect with just one peripheral member, Downing could immediately achieve almost a $20 \%$ improvement in cohesion of the network.

This ability to see the topology of the network, which turned out to be very different from the map she had in her head, yielded many such insights on how to finetune the network-as opposed to simply overloading already busy people with another collaborative tool, meeting, or conference call. For instance, employees within one subgroup were very cohesive, but they felt adrift with Smith's departure; he had helped this group win merger integration projects within a specific industry. Since Smith partnered with the group, they had won and completed five major projects with extremely high client satisfaction, but Downing, whose background was in transformational change, was not part of this subgroup's network. As a quick response, she developed a roster of people who could fill the impending network gap by attending virtual sessions focused on the subgroup's topics. Downing also took responsibility for developing relationships with key executives who were connected to each other solely through Smith. With an informed view of the network gaps Smith would create on his departure from the group, Downing was able to avoid inefficiencies and potential client losses.

In addition, Downing targeted key leaders in the organization to rapidly raise her practice's profile. Rather than letting history and inertia guide how the unit supported key areas of the organization, she used the net- work results to ensure that the right people were targeting the right external stakeholders. These individuals were asked to invite key account executives as guest speakers or participants to the bi-weekly business unit calls and to track information requests and resulting sales information. A structured agenda was developed to assist in initial conversations, focused on raising awareness of the unit's network, gaining insight into each other's expertise, and sharing knowledge assets. Though seemingly simple activities, these targeted conversations accelerated and extended collaborations, from employee referrals for job postings to joint proposal development. For example, Downing found out that one executive in another organizational silo had significant experience in managing organizational transformation. With Downing's encouragement, he began joining calls and assimilating into her practice. One year later, the combination of this executive's experience with the cutting-edge tools housed in Downing's group enabled them to partner on a substantial client project. Downing and the executive staffed the project across organizational lines to ensure a blended team that leveraged each group's strengths - the end result being a much more profitable project with enduring client impact.

The ONA also helped Downing determine how her business unit could more rapidly respond to new sales opportunities or client delivery needs. To be effective, all members of high-performing units must be aware of the expertise distributed throughout the network-not just of the knowledge and skills of the people they know well. So, along with the information network, Downing also mapped awareness of colleagues' expertise. The results clearly revealed that people in the network had a great deal to learn about relevant expertise and experience within the practice. Overall, $82 \%$ of the network was comprised of relationships where people indicated that they were unaware of colleagues' expertise. Although the skills and expertise of one or two employees were widely known (for instance, 56 out of the 69 members claimed to be aware of Smith's 
expertise), most were not. Well over half of the senior executives were known by nine or fewer colleagues.

Downing and others were concerned that this lack of awareness of "who knows what" and trust in other colleagues' expertise was invisibly leading to missed sales opportunities and less-than-optimal delivery of services. After all, how can you respond to a pressing proposal or client need if you don't even know whether the expertise to address this challenge exists in the practice, or whether you can trust people you have not worked with before to come through on commitments at the level that you need? She could recount stories where opportunities had been missed because employees were not aware of their colleagues' expertise. She took a series of actions to strengthen this network. First, she distributed simple profiles of each employee's expertise, recent project experiences, and some personal information (universities attended, hobbies, and other interests) that quickly began to prompt conversations between strangers. Second, she changed where people sat during faceto-face meetings and redesigned the format of the virtual calls the group had, to ensure that voices of peripheral people, whom she knew had valuable skills and experience, were heard. Third, she altered staffing practices to help connect people across network silos on both internal and external projects. Here the network results were very powerful in helping identify well-positioned people in each subgroup (across a silo) that helped to rapidly integrate the group overall.

She knew that most people, left to their own devices, choose to cluster with those they know and like, or to simply rely on people who are more central in the network. Though sometimes it was inefficient from a short-term economic perspective to staff people from different silos on a given project, she was convinced that creating a more robust network that understood and trusted in each others' skills would lead to much greater effectiveness over time. And she was right. Downing's efforts revealed pockets of expertise that could be linked to create much greater bench strength; no longer would the unit find itself unable to respond to client requests because it knew of only one or two subject matter experts in a suddenly popular field (e.g., talent management or decision making). In the past, Downing had always turned to the same one or two individuals each time she received an inquiry on a given topic. Now that she had better insight into expertise deeper within her organization, she found she was more effective in balancing work across her people, leveraging those who otherwise might have remained on the periphery of the network. This load balancing resulted in faster response time and higher-quality proposals; ultimately, it helped to triple her organization's reach into different client engagements over the next 18 months.

In addition to promoting awareness of expertise across silos, the network results also gave Downing some crucial insights regarding how to dissolve barriers that were keeping the unit from combining expertise in key areas and differentiating itself from its competitors. A quantitative presentation of the network data (Fig. 1b) helped her see the extent to which a pattern of recurring work assignments had created silos within and between key industry account groups and business units like Downing's. The table in Fig. $1 \mathrm{~b}$ shows the percentage of informationseeking relationships that existed within and between each function if every person were collaborating with every other person at that network juncture (either within or across units). For example, if everybody in High Tech had effective informational relationships with one another, the figure 100\% would appear in the top left-hand cell (instead of the actual 35\%). Of course, percentages in a table like this are affected by group size. It is much easier for a group of 10 to be fully connected than a group of 100 .

The table revealed several opportunities. Although Downing did not want to see high numbers in all the cells - everybody collaborating with everyone else would mean time was probably being wasted - she did want to see specific points of integration 
where fluid information flow was important to the success of the unit. First, looking down the diagonal, Downing hoped to see 25-35\% connectivity within each group, to ensure that best practices and synergies were being realized in groups that had similar expertise. Within Consumer Goods and Natural Resources, the figures were much lower. Downing knew that even though those functions were small, each had specialists who rarely worked together-yet collaboration among these specialists could help to develop truly unique service offerings.

Second, Downing was keenly interested in building certain off-diagonal collaborations that could yield a competitive advantage with clients-especially where bringing together people from different functions produced a holistic solution to clients' problems. These key off-diagonal junctures represented the greatest opportunity to combine unique, tacit expertise in offerings to clients that competitors could not recreate. Collaborations often break down for simple reasons-two leaders don't like each other; physical distance between people gets in the way; incentive schemes are incompatible; or there is a lack of technical infrastructure. The figures in this kind of grid help locate those breakdowns that undermine strategy execution. Note that this table of information-seeking relationships should be read from row to column. This allows one to see any substantial discrepancies in information flow between groups. For example, in this table, people in Government turn to those in High Tech, with 9\% (out of a possible 100\%) of information-seeking ties. In contrast, people in High Tech do not seek information from those in Government.

A key driver of network silos in this case was incentive schemes that encouraged inward-facing collaborations. Downing reevaluated her performance management system and realized that one key measurement was missing. Individuals were held accountable for billable time to client, sales goals, and developing publications and offerings, but they were not held accountable for collaborations that supported colleagues.
Downing stressed to her team that a major criteria in annual reviews moving forward would be personal impact in one of the industry groups. For example, having a strong review from an executive in an industry group explaining how someone added value to the project would result in a higher annual rating, and in turn, pay increase. This sent a clear message on the importance of bridging ties and had an almost immediate impact on collaboration overall.

In this case, Downing was keenly interested in improving collaboration between her unit's strategy practitioners and those in Banking, Government, and Natural Resources. The results showed very clear fragmentation at specific points. Downing addressed these by assigning liaison roles to help bridge groups where integration of expertise would lead to more holistic client offerings. Importantly, it allowed her to pick liaison roles by virtue of a person's strategic position in the network-well positioned people who could help knit subgroups together much more efficiently than choosing someone by virtue of formal role. These people were responsible for maintaining contact with the unit's executives, soliciting their advice when solving client problems, responding to project requests, inviting the executives as guest speakers or as participants in the bi-weekly practice calls, and turning to them as partners in sales efforts and projects. Downing also asked the liaisons to expand the unit's network within the overall firm and to become aware of other experts in the firm.

This targeted network development through liaisons resulted in two key outcomes. First, it strengthened the group's service offerings by including the latest and most relevant thinking on a given topic such as operating model development - tailored to the current challenges faced by a given industry. Second, through these collaborative efforts, Downing was able to have at least one individual from her direct team working on a client engagement within each of these desired practice areas. The practice's productivity, billable work, and client impact increased as a result. 


\section{DRIVING ECONOMIC RESULTS THROUGH EFFECTIVE COLLABORATION}

Downing knew that improvements in collaboration had to create measurable value to be sustainable. She anticipated measuring the impact of network improvements over time by tracking revenue, billable hours, and client retention and satisfaction. In addition, though, she also decided to assess value creation in the network itself, so she could cultivate relationships that would facilitate revenue growth and establish collaborations that would yield productivity gains. Downing used a network question ("Please indicate the extent to which you have been able to generate client revenue based on your interactions with each person below" - see Appendix A for response options) to determine where important revenue-generating collaborations existed, and where they needed to be built.

First, this view helped her to spot relationships where people were aware of colleagues' expertise but did not see an opportunity to collaborate on sales efforts-a visual that helped her determine whether key players in the network were thinking too parochially. Results revealed a set of five to six high performers who needed to learn how collaboration and integration could help them differentiate the firm's offerings. For example, an expert in Joint Ventures was deeply embedded within the Natural Resources group. Although she knew a few executives in the High Tech practice, she didn't realize an immediate opportunity for collaboration. Downing spoke with the executive to see whether the process to organize, staff, and govern a joint venture within the Natural Resources industry could be applied to a High Tech client. After a brainstorming discussion, the executives partnered to help a High Tech client successfully set up a joint venture. This is one example of many opportunities that would have continued to go unrealized had Downing not helped certain people in the network create a vision for how they could integrate expertise in client offerings.
Downing also identified "sweet spots" where collaboration had successfully generated revenue. She then segmented these networks to see who participated in the highestvalue collaborations (those greater than $\$ 2$ million) and who were involved in lowervalue collaborations (those under $\$ 250,000$ ). The analysis indicated that the 10 most connected people supported collaborations yielding $60 \%$ of the network's revenue, with the top five alone accounting for 38\% (see Fig. 2). Some of these people were wellrecognized leaders, but others were not, and represented clear vulnerabilities for the unit should they leave.

Downing's focus turned to two fronts here: (1) creating relationships that protected the group should these people leave (e.g., asking these people to take junior people with them on client calls) and (2) building collaborative behaviors more deeply into the performance measurement process so that the invisible behaviors of those supporting a wide number of other people were recognized and encouraged (in contrast to the traditional heavy focus on individual sales results). Further, by assessing the value of the collaborations, she was able to take specific action to encourage certain kinds of sales efforts. In a professional services organization like this one, prospective clients are not all equal; some represent significant revenue opportunities but low odds of a successful sale; others may not be as large in size, but the probabilities of a successful sale are much higher. Through the ONA, Downing was able to identify the clusters of people who consumed the time of her team but yielded the least revenue. With this knowledge, she was able to direct her team to focus on the high-probability sales, raising the quality of work delivered, and de-prioritize the lowprobability requests.

The second kind of value-creating collaborations Downing wanted to promote were those that helped others minimize non-productive or non-billable hours. She focused on this with a network question: "Please provide an estimate below for the typical time saved per month as a result of information, 


\section{Fig. 2 Network Value Creators}

\begin{tabular}{|c|c|c|c|}
\hline \multicolumn{2}{|c|}{$\begin{array}{c}\text { Monthly Time } \\
\text { Saved }\end{array}$} & \multicolumn{2}{|c|}{$\begin{array}{l}\text { Monthly Revenue } \\
\text { Generated }\end{array}$} \\
\hline Name & Hours (\%) & Name & $\$(\%)$ \\
\hline Chris S & $10 \%$ & Chris S & $12 \%$ \\
\hline Nancy W & $8 \%$ & Hewitt L & $9 \%$ \\
\hline LeAnn F & $6 \%$ & Elizabeth $\mathrm{N}$ & $7 \%$ \\
\hline Steve V & $5 \%$ & LeAnn F & $6 \%$ \\
\hline Bob L & $4 \%$ & Taylor H & $5 \%$ \\
\hline Dick C & $4 \%$ & Trevor C & $5 \%$ \\
\hline Lori K & $4 \%$ & Lori K & $5 \%$ \\
\hline Beth E & $3 \%$ & Dick C & $4 \%$ \\
\hline Xavier Z & $3 \%$ & Kari E & $4 \%$ \\
\hline Omar M & $3 \%$ & Zack T & $4 \%$ \\
\hline Kelly A & $3 \%$ & Beth C & $3 \%$ \\
\hline Ed Q & $3 \%$ & Graham Q & $3 \%$ \\
\hline $\mathrm{Ed} \mathrm{N}$ & $2 \%$ & Eugene R & $3 \%$ \\
\hline Tom L & $2 \%$ & Fanny N & $2 \%$ \\
\hline $\mathrm{Hal} \mathrm{L}$ & $2 \%$ & Kyle L & $2 \%$ \\
\hline Oscar Q & $2 \%$ & Steve V & $2 \%$ \\
\hline Zack T & $2 \%$ & $\operatorname{Ian} \mathrm{L}$ & $2 \%$ \\
\hline Stacy T & $2 \%$ & Kathy E & $2 \%$ \\
\hline Kathy E & $2 \%$ & Neil W & $2 \%$ \\
\hline Dave I & $2 \%$ & Rob V & $2 \%$ \\
\hline
\end{tabular}

advice, or other resources received from each person." By accumulating these responses and applying a loaded compensation figure (unique for each person in the network) to these time-savings estimates, Downing was able to estimate the efficiencies the network was generating. Further, by applying billing rates to these estimates, she got a sense of the revenue these knowledge-sharing interactions could help create by freeing up people's time.

The results again showed a heavy reliance on a small set of people. The top 10 people in the network returned $48 \%$ of the value generated through time saving, and the top five accounted for $32 \%$ of the total. Interestingly, though, the people valued for these time savings/knowledge-transfer purposes were, by and large, different from the top revenue facilitators (see Fig. 2). One very central person in the overall network turned out to be the staffing coordinator-an unlikely powerbroker in a network of highly paid executives. It turned out that she was a choke point in the staffing process. As she became overloaded with people contacting her, she began to operate at less than peak efficiency. This resulted in lower staffing levels for the unit, lower overall revenue generation, and lower operating margins. Adding two support staff dramatically reduced inefficiencies and also began to bump up unit billability.

The network analysis revealed that aggregate productivity benefits totaled $\$ 5.4$ million within the business unit and $\$ 5.9$ million between the business unit and the industry account groups. These financial figures allowed Downing to model the potential impact from network improvement efforts. For example, the targeted and low-cost effort to connect the key brokers and to get each of them to engage one peripheral person had 
the potential to yield an additional $\$ 2.9$ million (within the unit) and $\$ 6.1$ million (between the unit and the account groups) in savings. Similarly, those who respond in a timely manner, through a phone call to gain a better understanding of the request or an email with applicable materials, are very valuable and typically save the inquirer hours of research. To ensure these collaborative behaviors were embedded in the practice, Downing added them to the team's on-boarding, evaluation, and training processes and continued to monitor the rate at which the practice handled inquiries. In this light, such investments of people's time seemed a nobrainer in comparison with simply dumping another collaborative tool on everyone.

\section{DRIVING INNOVATION AND CROSS-SELLING}

Downing was keenly interested in leveraging the senior executives' expertise and their relationships to help the unit develop new client offerings. Hiring the right talent was a logical path to take; however, Downing was convinced that the unit's future success would depend on its ability to integrate unique skill sets in ways her competitors could not. Downing was pleased to see that roughly $20 \%$ of the ties that were critical to her group's performance involved people outside the company. These external ties to associations, clients, external subject matter experts, past colleagues, and others were an important source of innovation. An equally important source was the recombination of expertise and experiences distributed among the other $80 \%$ of important informational relationships.

In the assessment, Downing included a list of competencies she had identified as important to the unit. She asked people which ones they had and would be willing to share, and which ones they most wanted to develop. Many of these competencies were important differentiators for the group. In addition, when these competencies were integrated through the network in unique combinations, they generated substantial service line innovations and strategic differentiation in the market. So matching these networks - i.e., those where skills existed with those where skills were desired - provided some very natural and compelling mentoring relationships and staffing opportunities. In addition, the resulting profile of expertise was helpful in identifying strengths and areas for improvement (Fig. 3). For example, it established domains where the unit had a good deal of expertise, such as in mergers and acquisitions (M\&A). It also revealed domains where few skills existed, such as leadership and strategic change-both areas she considered to be important for future growth.

\section{Fig. 3 Centrality of Expertise in the Network}

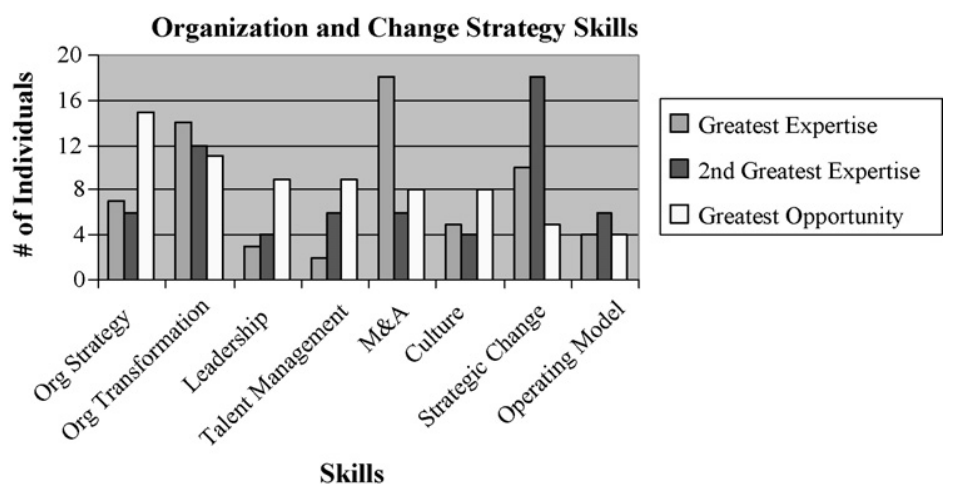


When combined with people's position in the network, these expertise ratings gave Downing a strategic view of the relative influence of skills within the practice. Her first concern was identifying the skill sets of the most central players in the network. Often the voices of a few network members can drown out novel ideas, driving sales efforts (as well as product/service development) along traditional trajectories. In the extreme, this can create an innovator's dilemma, in which a small group can become overly influential in defining what information and opportunities are deemed legitimate or worth pursuing. Downing learned that M\&A skills were central in the network and resulted in many repeat sales (Fig. 4).

Although this was positive from a revenue perspective, she also knew that M\&A work was very contingent on the economy, and so did not want to be overly reliant on this service line. Her group's long-term success would come only if it did not sell and deliver projects in a way that drove the practice into a niche market. Thus, when the ONA revealed clusters of expertise and interest in leadership development, talent management, and business operating models, Downing hastened to forge the lines of communication among individuals and seeded product development with small, but welcomed, grants of free time to codify knowledge and methods.

She also focused effort on skills that had become more peripheral and sought ways to draw experts back into the network. For example, individuals with expertise in joint ventures were reenergized and began publishing a monthly postcard with client experiences and recent publications. Alternatively, individuals with expertise in leadership development spent time learning the variety of methodology and tools among them and defined a new comprehensive product to meet client needs. The end result was a renewed excitement within these skill networks, and through these collaborations, a raised visibility throughout the organization.

\section{Fig. 4 M\&A Expertise is Central to the Network}

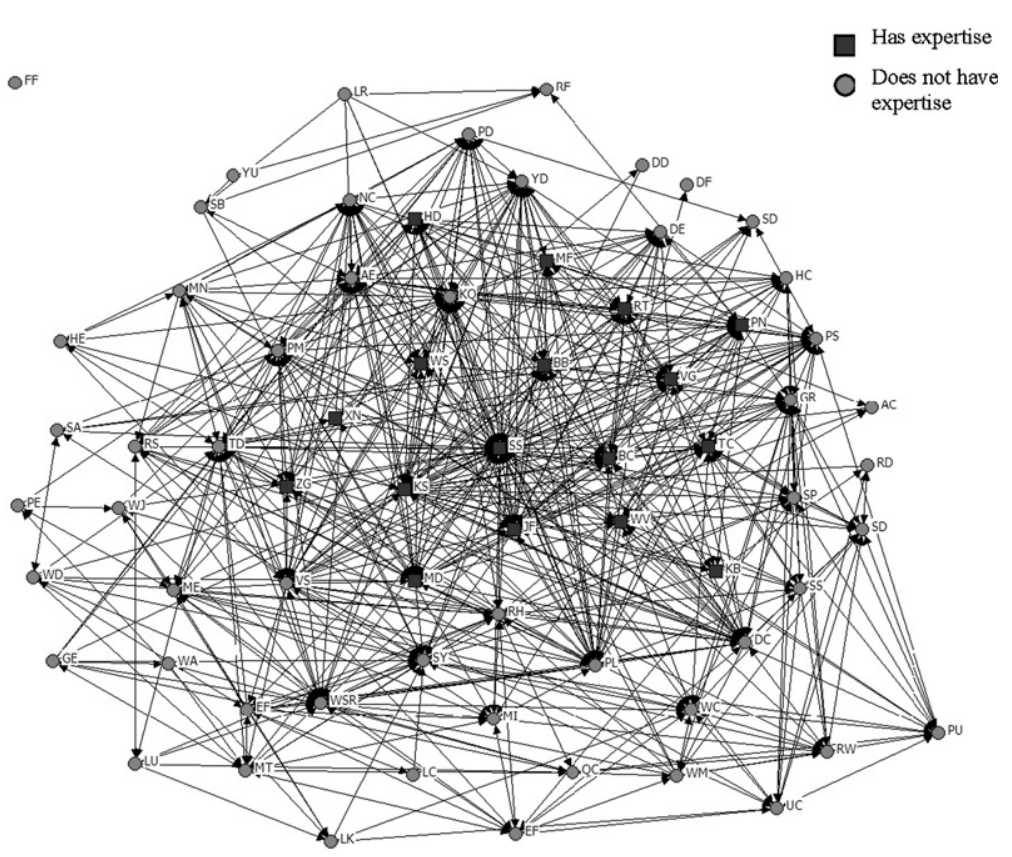


As a result, they became regularly sought out for their expertise, leading to sales opportunities and delivery of higher-quality products to clients.

\section{IMPROVING TALENT MANAGEMENT PROCESSES}

A final objective that Downing wanted to achieve through the network analysis was to find ways to more naturally and rapidly replicate the personal networks of high performers throughout her practice. Most of her employees knew that their network represented an important asset to their career and performance, but many failed to take the time to hone and develop important relationships (e.g., ties bridging outside the organization; peer relationships to brainstorm with, select ties up in the hierarchy to obtain legitimation and support). After the data collection for the ONA, a Web site was automatically generated for each person and provided a 15-"page" dynamic tour of his or her own connectivity. Specifically, the network profiles indicated how high performers build connections that yield an advantage on three dimensions: connections within a network that efficiently introduce new ideas and opportunities; targeted relationships that extend individual abilities and help people avoid learning and decisionmaking traps; and beliefs and behaviors that serve to build and maintain vibrant and helpful networks.

The individual diagnostics can help identify both the important dimensions to have in one's network and the traps high performers can fall into when they undertake network building without proper thought or discipline. As an example, for one leader it became quickly apparent that he had a robust network outside the organization and also people he sought out for career advice and a sense of purpose in his work (two key predictors of job satisfaction and retention that are often missing from people's networks). As his role changed, he indicated that he needed to revisit his network: A sense of impact or purpose became more important than problem solving and political support. He also wanted to make sure he had individuals in his network who actively challenged his thinking.

In another instance, a subject matter expert who struggled to achieve acceptable levels of sales and billability learned from his personal network profile that he spent an inordinate amount of time providing advice and support to peers with whom he had worked at another company, but who were themselves achieving mediocre results in Downing's unit. Rather than abandon them, he sought out durable connections with a wider array of senior executives. Though he admitted that this shift was hardly a blinding insight, he also insisted that he'd been stunned by the skewed (and non-reciprocal) nature of the relationships he saw in his profile. The first six months after receiving his profile, his billability and sales credits improved by $50 \%$.

Needing talented people from inside and outside the company, Downing faced three challenges. The first was finding ways to jumpstart newcomers' productivity. She didn't want to wait the traditional six to 18 months it usually takes for experienced hires to feel productive; she wanted to embed these people in the network rapidly and effectively. The second challenge was better leveraging of newcomers' relationships and ideas. In most cases (Downing's included), newcomers were not "heard" until they gained visibility and legitimacy in the eyes of their peers. The third was keeping experienced hires long enough to justify the costs of recruiting, hiring, and getting them up to speed. Research has shown that the probability of a new employee quitting reaches a peak after 1.5 years and declines rapidly after that. Clearly, helping newcomers past this entry stage would be critical to the group's long-term success (Rollag, K., Parise, S., \& Cross, R., 2005. Getting New Hires Up To Speed Quickly. Sloan Management Review, 46(2), 35-41).

Rather than providing newcomers with only a computer and a pat on the back, 
Downing implemented a systematic means for newcomers to rapidly build a network that would help them succeed. She decided to pay special attention to new hires and help them get better integrated. The network analysis allowed her to plot connectivity against tenure and to see those who were integrating into the group well as well as those who were struggling. She also began implementing simple practices to help connect newcomers in their first six weeks. For example, a moribund program of career counseling was reinvigorated. Upon arrival in the unit, new hires were immediately given 10 people with whom to connect for critical bits of information about their jobs. Another network was established: one made up of entry-level employees who met via teleconference on a bi-weekly basis to discuss common project issues. Finally, a "shadowing" program was established that put new hires on a client project for three weeks at no cost to the client other than travel and hotel expenses. A reassessment of Downing's practice one year later showed a remarkable difference. Due to her efforts, the group was extremely integrated, with multiple connections to and from the newcomers. As one newcomer put it, "The effort everyone makes to help integrate you really shows. You know people care and it makes all the difference."

Downing was also keen to use the analysis to lessen the impact of knowledge loss by identifying employees whose departure could fragment a network, and by specifying unique kinds of knowledge loss that occur when people in central, broker, and peripheral network positions leave. Loss of the key players identified in Fig. 1a was a significant potential threat to the network. In addition, Fig. 2 showed a number of people who could dramatically but invisibly reduce the profitability of the group should they leave the firm or get rotated or promoted out of the unit. Looking for ways to promote the connectivity of these people - through staffing, mentoring, and internal projects - was an important task Downing assigned to the staffing coordinator.

Finally, although the network analysis revealed that there was redundancy in the
M\&A domain, it also revealed only one or two well-connected players in leadership. Losing these people would create a capability loss that training, mentoring, and hiring (along with network on-boarding practices) could help minimize or prevent altogether. The first step was to document their knowledge and train others on the offerings and tools, which they did through presentations and virtual training seminars. As with many consulting firms, the key to credibility was experience. Downing sought ways to get high performers interested in leadership development by working on projects with the subject matter experts, simultaneously gaining experience and coaching and developing the bench strength within her group. Once those individuals had leadership development experience under their belt, she could recommend them for other similar projects and could publish their recent experience on their profiles, resulting in higher connectivity of these individuals.

\section{TRACKING PROGRESS}

Armed with a much better understanding of the group and recommendations for improving its overall positioning and capabilities, Downing felt confident that she could continue where Smith left off. With remarkably little effort (roughly 20 minutes of employees' time to complete the customized on-line diagnostic), she was able to uncover a wide array of high-leverage opportunities to improve the unit's performance. Determined to succeed, Downing implemented some relatively low-cost interventions immediately and created a project plan to continue managing interventions throughout the year.

By the end of 2006, a range of evidence indicated that efforts to improve collaboration in value-added ways were paying off. For example, the percentage of the group's time that was billable to clients more than doubled, reaching nearly $60 \%$ in the fall of 2006. At the same time, the ratio of managers to analysts was declining rapidly, which meant better leverage and that new, more 
junior people were being brought on board, embedded well in the network and made productive more rapidly than had traditionally been the case. Downing's group was regularly tapped to pitch on large proposals-with her team's expertise serving as a key differentiator from key competitors. Through these collaborative sales efforts, she helped win $\$ 1 \mathrm{MM}+$ engagements, as well as several small, high-impact engagements with high potential for follow-on work. An ONA on Downing's group one year later, in August 2006, showed that $74 \%$ of the group was connected. It was beyond her expectations, especially given the growth of her group, and she was thrilled to see such an impact.

Despite the progress made, Downing knew that the initial network redesign could not be a one-time effort. The improvement in results could be multiplied if she continued to pay attention and closely monitor the evolution of the team's internal and external networks. The journey had just started, and Downing knew it well. However, she was pleased with the progress that had been made and the dramatic return for her and her practice in terms of performance.

\section{NETWORK ANALYSIS IMPLICATIONS FOR MANAGERS}

Others can benefit from application of the network ideas to unique groups where collaboration is central to innovation and performance. In addition to Downing's focus on business unit effectiveness, a network perspective provides a unique means to promote innovation. Conventional wisdom suggests that innovation will flourish if the right expertise is brought in house and the right processes are followed. Applying a network perspective reveals three specific traps that organizations fall into when they don't consider the distribution of expertise in the network: (1) Fragmentation. Collaboration often breaks down across physical distance, functional lines, technical capabilities and occupational sub-cultures in ways that invisibly undermine strategic innovation efforts. (2) Domination. Akin to an "Innovator's Dilemma" trap, the voices of a few central network members can drown out novel ideas, driving innovation efforts along traditional trajectories long after the market has veered in another direction. (3) Insularity. Inability to recognize and leverage relevant external expertise can yield excessive cost structures and time delays that result in missed market opportunities. The ability to visualize these traps informs a wide range of interventions, such as altering brainstorming or project start up practices, revising staffing programs and implementing technologies that help to bring the right capabilities and resources together at the right point in time.

Executives also often apply a network perspective in large scale change processes by working through a network's structure as well as integrating network and culture assessments. As one example of working through informal structure, the network assessments help to locate key brokers in a network. Brokers often do not have the most connections, but rather are important because they have a high number of ties connecting sub-groups. As a result of their bridging ties, brokers uniquely knit an entire network together and are the most efficient route to get information about a change process diffused through a group. They also tend to have the best perspective on what aspects of a redesign will work across different sub-groups and are unique in the ground-level credibility they have with people from disparate functions, locations or occupations. In short, brokers are the people whom change agents want on design and implementation teams as well as communicating about a change effort.

Alternatively, understanding how values, norms and goals are distributed in networks throughout an organization provides more powerful levers for change than typical culture or employee opinion surveys. For example, a common archetype is to see that one group of people who are most positive on a cultural dimension and another 
who are most negative are BOTH central in information and influence networks. In standard culture assessments, these people average out-but with a network perspective, leaders have a dramatically different view of how and where to build momentum through the positive culture carriers (e.g., getting certain culture carriers into transition teams and as focal points for communication efforts) and help diminish the impact of negative culture carriers (e.g., coaching or providing greater voice in the process to those who have become disillusioned).

A network perspective can also yield targeted insights on ways to drive sales. For example, a network analysis can be conducted at the client interface to improve revenue production and retention of key accounts. When using ONA to evaluate account team performance, we focus on four critical success factors: (1) Quality of relationships between the account team and client. Diverse, high-quality client connections across several team members allows for better customer service, discovery of crossselling opportunities and decreased susceptibility to departure of key individuals on either side. (2) Quality of relationships within the account team. A well-connected team and strong personal networks allow professionals to identify and capitalize on opportunities. (3) Quality of relationships back into the company providing goods/services. Success depends on the ability to draw on the pro- viding company at large for expertise and connections that don't reside on the team. (4) Team structure, behaviors and practices. Effectiveness depends on fundamental alignment within the team, including clear goals, roles and responsibilities, and encouragement to collaborate.

Alternatively, efforts focused at the individual network level on sales force productivity can drive substantial returns by helping lower-performing employees understand and then replicate the networks of high performers. In sales force productivity applications, we have almost universally found that the high and low performers are delivering the same product messages and using the same sales management practices-they have all been to the same training programs, after all. What distinguishes the high performers and provides a performance kick to an organization comes from understanding and then replicating their networks more rapidly throughout the sales force in on-boarding and career management practices. Overall, when you can visualize the network and systematically intervene and experiment with it to see the results both in people and financial terms, it becomes possible to grow an adaptive organization on a wide range of fronts.

To order reprints of this article, please call +1 (212)633-3813 or e-mail reprints@elsevier.com 


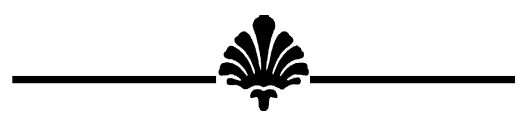

\section{SELECTED BIBLIOGRAPHY}

For some time, research has indicated the extent to which people rely on other people for information to get their work done. Yet understanding and being able to take action on these collaborations in a targeted way has remained a challenge for many organizations. Whether learned in business school or as a product of experience, many executives treat the informal structure of an organization as something to be managed around in a change process rather than a structure to be understood and leveraged for performance and innovation impact. Making these invisible interactions visible and actionable is at the heart of what network analysis can offer executives, as recent work in this field has shown. In this regard, see R. Cross \& A. Parker, The Hidden Power of Social Networks (Boston: Harvard Business School Press, 2004); and M. Gladwell, The Tipping Point: How Little Things Can Make A Big Difference (Boston: Back Bay Books, 2002).

Two streams of literature heavily influenced our thinking in the development of this case. First is research from the social network tradition that has shown the extent to which information that affects what people do and think largely comes from other people in their networks. Some important works on how social networks influence information flow and diffusion in networks include G. Simmel, The Sociology of Georg Simmel (New York: Free Press, 1950); R. Burt, Structural Holes (Cambridge, MA: Harvard
University Press, 1992); M. Granovetter, "The Strength of Weak Ties," American Journal of Sociology, 1973, 78, 1360-1380; T. Allen, Managing the Flow of Technology (Cambridge, MA: MIT Press, 1984); P. Monge \& N. Contractor, "Emergence of Communication Networks," in F. Jablin \& L. Putnam (Eds.), The New Handbook of Organizational Communication (Thousand Oaks, CA: Sage, 2004), 440502; E. Rogers, Diffusion of Innovations, $4^{\text {th }} \mathrm{Ed}$. (New York: Free Press, 1995).

Although impactful, this approach has focused almost exclusively on the structural aspects of networks and not paid much attention to the right relationships to map. In this work, we also sought to leverage rich ethnographic evidence accumulating within the situated learning and community of practice traditions. Some important work in this tradition includes J. S. Brown \& P. Duguid, "Organizational Learning and Communities-of-Practice; Toward a Unified View of Working, Learning and Innovation," Organization Science, 1991, 2(1), 4057; Brown \& Duguid, The Social Life of Information (Cambridge, MA: Harvard Business School Press, 2000); J. Lave \& E. Wenger, Situated Learning: Legitimate Peripheral Participation (Cambridge, UK: Cambridge University Press, 1991); J. Orr, Talking About Machines (Ithaca, NY: Cornell University Press, 1996); and E. Wenger, Communities of Practice (Oxford, UK: Oxford University Press, 1998).

Rob Cross is a professor of management at the University of Virginia and research director of The Network Roundtable, a consortium of 75 organizations sponsoring research on network applications to management issues. His research focuses on how networks in organizations can be analyzed and improved to promote competitive advantage, innovation, customer retention and profitability, leadership effectiveness, talent 
management and quality of work life. In addition to top scholarly outlets, his work has been published in Harvard Business Review, Organizational Dynamics, Sloan Management Review, California Management Review, McKinsey Quarterly and Academy of Management Executive. His most recent book, The Hidden Power of Social Networks, has been featured in venues such as Business Week, The Financial Times, Time, Fortune, The Wall Street Journal, CIO and Inc. (Tel.: +1 434924 6475; e-mail: robcross@virginia.edu).

Bob Thomas is executive director of Accenture's Institute for High Performance Business and the John R. Galvin Visiting Professor of Leadership at the Fletcher School of Law and Diplomacy at Tufts University. Thomas specializes in the areas of leadership, organization design and transformational change and is co-author with Warren Bennis of "Geeks and Geezers" and the forthcoming book, "Leading for a Lifetime" (both from Harvard Business School Press).

Ana Dutra is the global managing partner for Accenture's global organization strategy practice, a $\$ 400 \mathrm{MM}$ global practice with over 100 senior consultants. Her management consulting experience comprises over 18 years across multiple industries as well as several years in sales, strategic planning, and as a college professor of economics. Prior to joining Accenture, Ana headed the organizational transformation practice at Mercer Management. Prior to that, she was a partner with CNA Consulting, a principal with CSC Index and Marakon Associates and spent eight years with IBM Corp. Dutra received an M.B.A. from Northwestern University's Kellogg School of Management, a J.D. from Universidade do Estado do Rio de Janeiro and a Masters in Economics from Pontificia Universidade Catolica.

Carrie Newberry is a senior manager in Accenture's global organization strategy practice. She has supported Fortune 500 clients though large scale organizational change initiatives, including internal restructurings, mergers, acquisitions and joint ventures. Her principle focus is in organizational network analysis, cultural change and organization design. Prior to Accenture, Newberry led strategic change initiatives at a large Internet services company. She received a Bachelor of Business Administration in marketing from James Madison University, where she graduated Summa Cum Laude. 


\section{APPENDIX A. ABRIDGED NETWORK SURVEY}

\section{BOUNDED NETWORK QUESTIONS \\ Information Effectiveness}

Please indicate the extent to which the following people are effective in providing you with information that helps you to learn, solve problems, and do your work. For timesaving purposes, select "set all to 0 " and adjust for those people with whom you frequently interact.

0 . I do not know this person/have never met this person

1. Very ineffective (very untimely, meaningless, or irrelevant information)

2. Ineffective (untimely, meaningless, or irrelevant information)

3. Somewhat ineffective (somewhat untimely, meaningless, or irrelevant information)

4. Somewhat effective (somewhat timely, meaningful, or relevant information)

5. Effective (timely, meaningful, or relevant information)

6. Very effective (very timely, meaningful, or relevant information)

\section{Revenue}

Please indicate the extent to which you have been able to generate client revenue based on your interactions with each person below.

$1=$ We have not interacted in a client sale scenario and I do not see the potential to do so.

$2=$ We have not interacted in a client sale scenario but I do see the potential to do so.

$3=$ We have interacted in a client sale scenario where collaboration did not result in a sale.

$4=$ We have interacted in a client sale scenario where collaboration was required to generate a sale under $\$ 500,000$.
$5=$ We have interacted in a client sale scenario where collaboration was required to generate a sale of \$500,000-\$1MM.

$6=$ We have interacted in a client sale scenario where collaboration was required to generate a sale of \$1MM-\$2MM.

$7=$ We have interacted in a client sale scenario where collaboration was required to generate a sale of $\$ 2 \mathrm{MM}+$.

\section{Time Savings}

Please provide an estimate below for the typical time saved per month as a result of information, advice, or other resources received from each person:

1. No time saved

2. 1-3 hours per month

3. $4-8$ hours per month

4. 9-12 hours per month

5. More than 12 hours per month

\section{Personal Network}

Please identify up to 10 people who are important to you in your professional network. These can be people who provide you with information or resources to do your work, help you think about complex problems posed by your work, or provide developmental advice or personal support helpful in your day-to-day working life. These may or may not be people you communicate with on a regular basis and can come from within this organization or outside (e.g., associates at other sites, friends in other organizations, suppliers, former classmates, family).

You must enter at least four names to receive a personal network report with benchmarks and group findings once the survey has been completed and closed.

\section{Question: Please indicate where each of these people works.}

- Member of my current project.

- Outside my project, within my practice. 
- Outside my practice, within my function.

- Outside my function, within the organization.

- Outside organization.

\section{Question: Please indicate each person's} hierarchical level relative to your own.

- Higher than mine.

- Equal to mine.

- Lower than mine.

- Does not apply.

Question: I typically look forward to and am energized by my interactions with each person.

- Strongly disagree.

- Disagree.

- Neutral.

- Agree.

- Strongly agree.

Question: Please indicate the primary benefit that you currently receive from each person below.

- Information that helps me to solve problems or capitalize on opportunities.

- Access to decision makers that allows me to move plans ahead.

- Political support that allows me to move my plans ahead.
- Problem-solving interactions that actively challenge my thinking on problems or opportunities in my work.

- Career advice or other developmental feedback that helps me be more effective in my work.

- Personal support and the ability to vent or discuss a tough problem in my work in ways that help me to get back on track.

- Purpose or a sense that what I do at work has a positive impact and matters.

Question: Please indicate the primary benefit that you would like to receive from each person below.

- Information that helps me solve problems or capitalize on opportunities.

- Access to decision makers that allows me to move plans ahead.

- Political support that allows me to move my plans ahead.

- Problem-solving interactions that actively challenge my thinking on problems or opportunities in my work.

- Career advice or other developmental feedback that helps me be more effective in my work.

- Personal support and the ability to vent or discuss a tough problem in my work in ways that help me to get back on track.

- Purpose or a sense that what I do at work has a positive impact and matters. 